\title{
Post-Operative Adding-On in Adolescent Idiopathic Scoliosis, A Particular Etiology: Conflict Between the Upper Articular Process and the Instrumentation Material : A Case Report
}

Mahdi Siala*, Daniel N'Dele, Franck Accadbled and Jerome Sales De Gauzy

CHU Toulouse, Children's Hospital 330 Avenue De Grande-Bretagne Toulouse, Haute-Garonne, France

\begin{abstract}
The aim of surgical treatment of adolescent idiopathic scoliosis (AIS) is to achieve a balanced spine. Distal addingon is a postoperative phenomenon in AIS, which is characterized by a progressive correction loss. A 13-Year-old girl with AIS who underwent posterior arthrodesis showed aggravation of the disequilibrium under the last instrumented vertebra (LIV) 30 months post operatively and an increase of the lumbar curvature with no evident cause. Extension surgery was made and per operatively we noticed that the distal end of the arthrodesis was disengaged and that the left rod was conflicting with the upper left articular process of L2. Among the causes of adding-on we report in this article a particular etiology that consists in a conflict with the instrumentation material. This conflict has to be looked for postoperatively if an adding-on phenomenon is suspected in addition to a distally protruding rod, and could motivate a CT scan imaging for diagnosis.
\end{abstract}

Keywords: Scoliosis; Idiopathic; Adolescent; Adding-On; Conflict; Instrumentation; Posterior Arthrodesis

\section{Introduction}

The aim of surgical treatment of adolescent idiopathic scoliosis (AIS) is to achieve a balanced spine in the coronal and sagittal planes without listing (deviation in C7-center sacral vertical line) or truncal shifting. In the selection of fusion levels, an ideal fusion mass requires parallel top and bottom endplates without substantial coronal shift, and appropriate sagittal alignment. Distal adding-on is a postoperative phenomenon in AIS, which is characterized by a progressive correction loss due to an increase in either vertebral deviation of the lumbar spine or disc angulation below the instrumentation. Distal adding-on is often accompanied by unsatisfactory clinical outcome and a high risk of reoperation, the incidence of adding-on has been reported to be $2 \%$ to $13 \%$ [1-3]. Adding-on has been observed in patients, especially those with remaining growth potential, with residual shoulder imbalance, inappropriate lowest instrumented vertebrae (LIV), and residual apical translation [4].

We report a particular etiology of adding-on and post-operative imbalance due to a conflict between the distal end of the rod and the upper articular process of the lower adjacent vertebra (LIV+1).

\section{Case Report}

A 13-year-old girl with AIS was planned for surgery. Preoperative Cobb angle were $60^{\circ}$ thoracic, and $31^{\circ}$ lumbar (Figures 1 and 2). On bending Cobb angle were respectively $60^{\circ}$ thoracic and $7^{\circ}$ lumbar on the left bending and $41^{\circ}$ thoracic and $53^{\circ}$ lumbar on the right bending. According to Lenke criteria [5,6], instrumentation was T4 to L1 using hooks, screws and rod (Legacy, Medtronic ${ }^{\oplus}$ Dublin, Ireland) and sub laminar clamps (Implanet ${ }^{\oplus}$ Martillac, France) at the apex. We didn't have any postoperative complication and the patient was discharged 8 days after surgery. Nevertheless, on the post-operative X-ray, (Figure 3) we noted imbalanced spine and decided to do a conservative treatment with physiotherapy.

At 6 months postoperatively, sports were authorized and return to normal activity without any limitation was achieved. Regular follow up until 30 months showed aggravation of the disequilibrium under the LIV (Figure 4) and an increase of the lumbar curvature with no evident cause. That was only partially corrected with 3 points cast

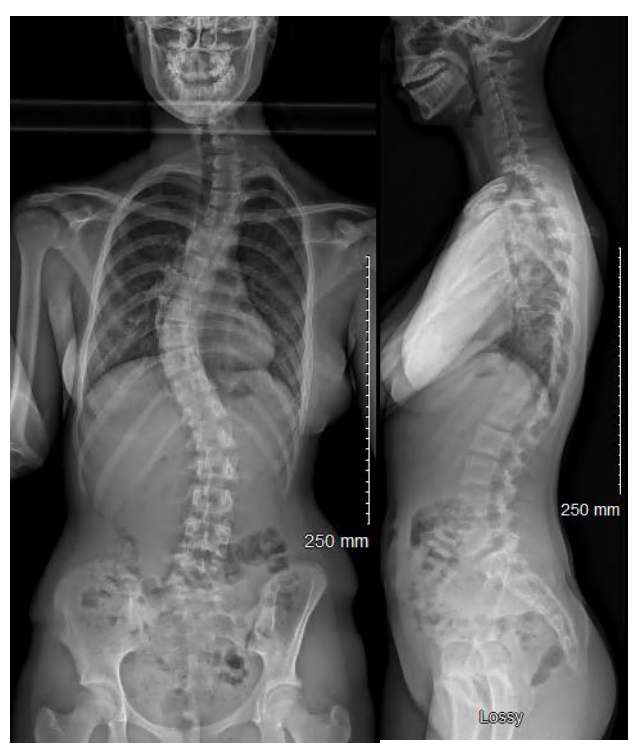

Figure 1: AP and lateral spine $\mathrm{X}$-ray prior to surgery.

therefor indicating an extension of the arthrodesis. So we decided to extend the instrumentation to the lumbar curve. Per operatively we noticed that the distal end of the arthrodesis was disengaged and that the left rod was conflicting with the upper left articular process of L2 (Figure 5). This explained the inclination of the vertebra responsible for the lumbar deviation and adding-on. The extension consisted in the ablation of L1 material and screwing L3 and L4 bilaterally and then

*Corresponding author: Mahdi Siala, CHU Toulouse, Children's Hospita 330 avenue de Grande-Bretagne Toulouse, Haute-Garonne, France, Tel: +33679118989; E-mail: mahdisiala@hotmail.com

Received April 24, 2018; Accepted May 07, 2018; Published May 09, 2018

Citation: Siala M, N'Dele D, Accadbled F, De Gauzy JS (2018) Post-Operative Adding-On in Adolescent Idiopathic Scoliosis, A Particular Etiology: Conflict Between the Upper Articular Process and the Instrumentation Material : A Case Report. J Spine 7: 415. doi: 10.4172/2165-7939.1000415

Copyright: (c) 2018 Siala M, et al. This is an open-access article distributed under the terms of the Creative Commons Attribution License, which permits unrestricted use, distribution, and reproduction in any medium, provided the original author and source are credited. 
Citation: Siala M, N'Dele D, Accadbled F, De Gauzy JS (2018) Post-Operative Adding-On in Adolescent Idiopathic Scoliosis, A Particular Etiology: Conflict Between the Upper Articular Process and the Instrumentation Material : A Case Report. J Spine 7: 415. doi: 10.4172/21657939.1000415

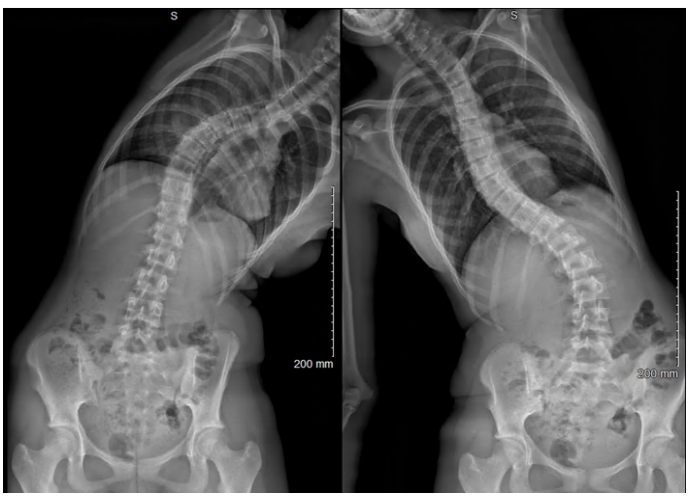

Figure 2: Lateral bending spine X-ray prior to surgery.

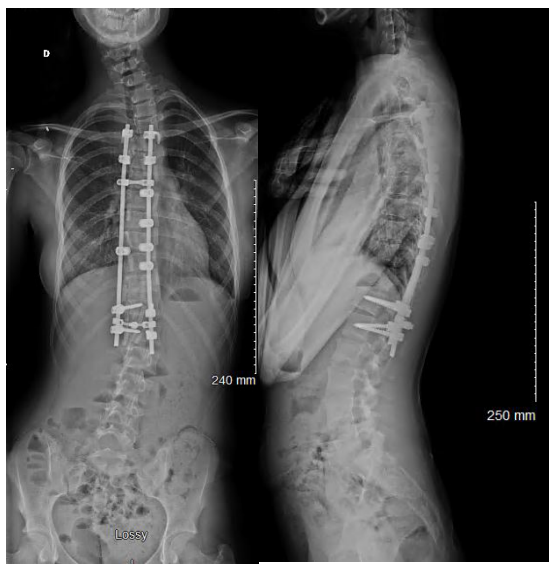

Figure 3: AP and lateral spine X-ray immediate post-operative.

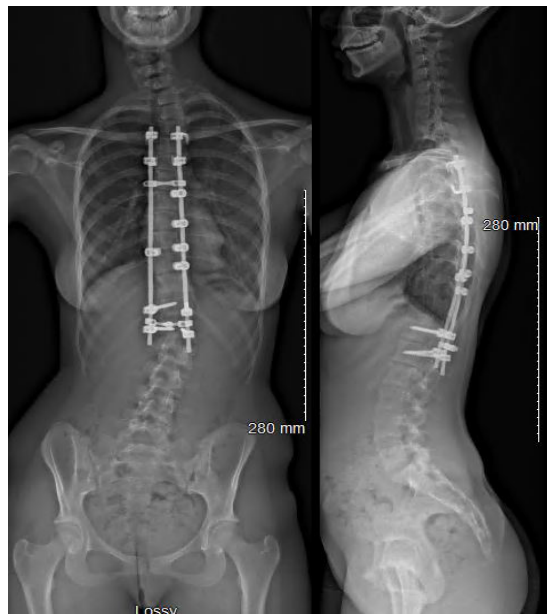

Figure 4: AP and lateral spine $X$-ray at 30 months Follow-up.

extending with two shorts rods and two connectors. Post-operative $\mathrm{X}$ ray showed correction of lumbar curve and a good balance of the spine (Figure 6). We didn't have postoperative complication and patient was discharged 5 days after surgery.

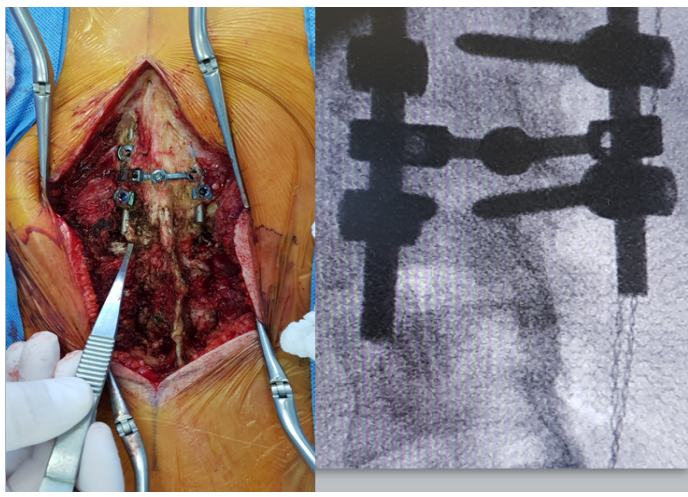

Figure 5: Pre-operative view and fluoroscopy of the adding-on phenomenon due to the conflict.

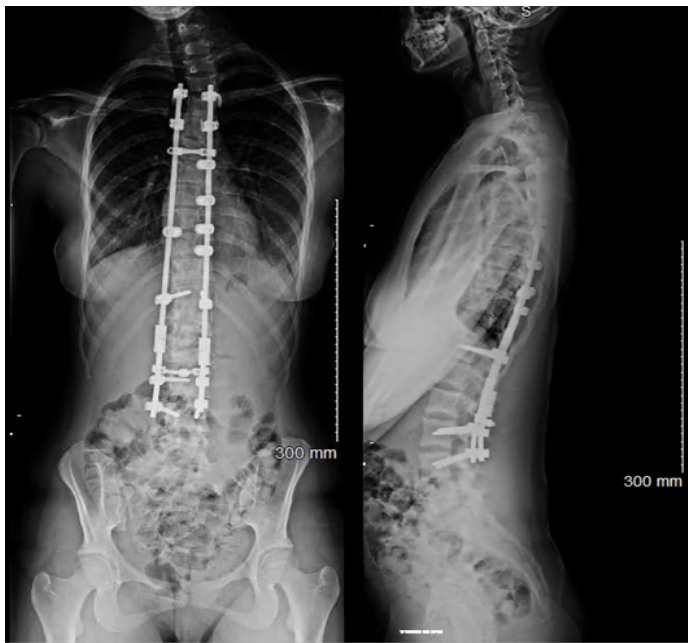

Figure 6: $\mathrm{AP}$ and lateral spine $\mathrm{X}$-ray after adding-on surgery.

\section{Discussion}

The adding-on phenomenon is a complication that can occur after surgery in AIS patients [7] and is defined as a progressive increase in the number of vertebra included in the main curvature of a scoliosis combined with an increase in the deviation of the first vertebra below the LIV or an increase in the angulation of the first disc below the LIV $[8,9]$. Parisini and Sponseller an co-authors $[10,11]$ both verified the adding-on phenomenon after selective thoracic surgery and can be caused by a wrong choice of LIV in selective thoracic fusion, especially if the patient presented skeletal immaturity $[3,12,13]$. Adding-on often leads to the progressive loss of curve correction and unsatisfactory clinical outcomes, as well as a high risk of reoperation [3].

A contradiction exists between increased spine fusion to prevent scoliosis progression and preservation of more of the segment to obtain better lumbar activity. In this report the limits chosen to the spinal construct were correct according to the Lenke criteria $[1,2]$ and following authors $[6,14]$ we explain the mechanical conflict between the arthrodesis material lower end and the upper articular process of the LIV+1 that was repulsed causing the LIV to rock as another possible etiology. 
Citation: Siala M, N'Dele D, Accadbled F, De Gauzy JS (2018) Post-Operative Adding-On in Adolescent Idiopathic Scoliosis, A Particular Etiology: Conflict Between the Upper Articular Process and the Instrumentation Material : A Case Report. J Spine 7: 415. doi: 10.4172/21657939.1000415

Page 3 of 3

\section{Conclusion}

Among the causes of adding-on we report in this article a particular etiology that consists in a conflict with the instrumentation material. This conflict is to be looked for postoperatively if an adding-on phenomenon is suspected in addition to a distally protruding rod, and could motivate a CT scan imaging for diagnosis.

\section{References}

1. Lehman RA Jr, Lenke LG, Keeler KA, Kim YJ, Buchowski JM, et al. (2008) Operative treatment of adolescent idiopathic scoliosis with posterior pedicle screw-only constructs: Minimum three-year follow-up of one hundred fourteen cases . Spine (Phila Pa 1976) 33: 1598-1604.

2. Lenke LG, Edwards CC, Bridwell KH (2003) The Lenke classification of adolescent idiopathic scoliosis: How it organizes curve patterns as a template to perform selective fusions of the spine. Spine (Phila Pa 1976) 28: S199-207.

3. Schlechter J, Newton P, Upasani V, Yaszay B, Lenke L, et al. (2009) Risk factors for distal adding- on identified: What to watch out for. Am Assoc Orthop Surg Ann Meeting 8: S164.

4. Wang Y, Hansen ES, Høy K, Wu C, Bünger CE (2011) Distal adding-on phenomenon in Lenke $1 \mathrm{~A}$ scoliosis: risk factor identification and treatment strategy comparison. Spine (Phila Pa 1976) 36: 1113-1122.

5. Lenke LG, Bridwell KH, Baldus C, Blanke K (1992) Preventing decompensation in King type II curves treated with Cotrel-Dubousset instrumentation. Strict guidelines for selective thoracic fusion. Spine (Phila Pa 1976) 17: S274-81.

6. Lakhal W, Loret JE, De Bodman C, Fournier J, Bergerault F, et al. (2014) The progression of lumbar curves in adolescent Lenke 1 scoliosis and the dista adding-on phenomenon. Orthop Traumatol Surg Res 100: S249-254

7. Wang Y, Bünger CE, Zhang Y, Wu C, Li H, et al. (2013) Distal adding-on in Lenke 1A scoliosis: How to more effectively determine the onset of dista adding-on. Spine (Phila Pa 1976) 38: 490-495.

8. Suk SI, Lee SM, Chung ER, Kim JH, Kim WJ, et al. (2003) Determination of distal fusion level with segmental pedicle screw fixation in single thoracic idiopathic scoliosis. Spine (Phila Pa 1976) 28: 484-491.

9. Suk SI, Lee SM, Chung ER, Kim JH, Kim SS (2005) Selective thoracic fusion with segmental pedicle screw fixation in the treatment of thoracic idiopathic scoliosis: More than 5-year follow-up. Spine (Phila Pa 1976) 30: 1602-1609.

10. Parisini P, Di Silvestre M, Lolli F, Bakaloudis G (2009) Selective thoracic surgery in the Lenke type 1A: King III and King IV type curves. Eur Spine J 18: $82-88$

11. Sponseller PD, Betz R, Newton PO, Lenke LG, Lowe T, et al. (2009) Differences in curve behavior after fusion in adolescent idiopathic scoliosis patients with open triradiate cartilages. Spine (Phila Pa 1976) 34: 827-831.

12. Yang C, Li Y, Yang M, Zhao $Y$, Zhu X, et al. (2016) Adding-on phenomenon after surgery in Lenke type 1, 2 adolescent idiopathic scoliosis: Is it predictable? Spine (Phila Pa 1976) 41: 698-704.

13. Risser JC (2010) The classic: The iliac apophysis: An invaluable sign in the management of scoliosis. 1958. Clin Orthop Relat Res 468: 643-653.

14. Wang $Y$, Hansen ES, Hoy K (2011) Distal adding-on phenomenon in Lenke $1 \mathrm{~A}$ scoliosis: Risk factor identification and treatment strategy comparison. Spine (Phila Pa 1976) 36:1113-1122. 